\title{
Respirar fundo
}

\section{Susana Paiva ${ }^{1}$}

Respirar fundo. Respirar fundo foi, durante muito tempo, a minha única solução para ganhar a necessária coragem e responder afirmativamente aos pedidos de organização do meu portefólio.

Seleccionar sempre me aterrou. Eliminar conjuntos de imagens, por vezes referências únicas a trabalhos com uma certa companhia, e criar argumentos sustentáveis para uma escolha do nosso próprio trabalho - sejam eles de ordem estética, técnica ou mesmo contextual - sempre me pareceram tarefas injustas e particularmente solitárias.

Seleccionar é condenar, precocemente, imagens a uma morte que, dessa forma, as impedirá de ver a luz do dia, elevando outras, certamente sínteses imperfeitas, à condição de ícone.

Acredito, e teimarei em acreditar, numa prática fotográfica múltipla e de partilha. Albergo o persistente e secreto desejo de encontrar um tempo e um espaço onde haja lugar para a cumplicidade da escolha.

Seleccionar é já interpretar. Reinterpretar um olhar, fazer juízo da beleza, significado e relevância de uma imagem.

Na fotografia de espectáculo, como em todas as outras áreas, estar à altura das expectativas é a mais dura e, porventura, dolorosa experiência. Fotografar é também aprender a viver espartilhado no delicado equilibrio entre a nossa mundividência e a visão do mundo dos outros. Traduzir, em imagens, a essência de algo tão complexamente expresso por corpos que cruzam luzes ao ritmo de voláteis sons num espaço não obedece a regras nem oferece fórmulas de sucesso.

Fotografar espectáculos é tão intenso como estar vivo. Depende sobretudo da capacidade, diária e individual, de interpretar e de acreditar no sentido e na beleza das coisas que se nos apresentam.

Estar vivo é deixar-nos tocar pela vida e poesia que brota de alguns espectáculos. É compreender que, não obstante as nossas preferências estéticas e formais, há espectáculos que nos devolvem a magia e o mistério que, por vezes, falta ao quotidiano.
Confesso que o novo circo me despertou para uma renovada forma de efabulação - uma possibilidade de viagem já tão remota em algumas outras práticas artísticas. Chamem-Ihe facilitismo, o que quiserem. A verdade é que lá encontrei artistas completos, cujas vozes e corpos me induziram em espaços de fantasia e encantamento que eu própria havia já esquecido.

Em Évora, durante os Percursos, depois do espectáculo de Camille Boitel - inclassificável, ouso dizer -, ouvi claramente diversos outros artistas participantes apelidarem-no de "fenomenal" ou mesmo de "inacreditável". Inexplicáveis minutos de prazer sensorial e intelectual, os de 0 homem de Hus. Primitivo e simultaneamente sofisticado. "Conceptual" ouvi, mais tarde, Camille dizer acerca do seu trabalho.

Um ano depois, ainda no âmbito dos Percursos, recebi mais duas dádivas de puro prazer - os Baro d'Evel que transportaram na magia do seu Bechtout os sons da tradição romani, tão delicadamente conjugados com o seu contagiante humor francês, e os portugueses Circolando que transformaram os espaços por onde passaram em calorosos e surpreendentes mecanismos de sedução de público.

Na praça do Giraldo, em Évora, os Circolando libertaram os seus homens-toupeira, herdeiros de uma reinventada tradição musical mineira e, no seu carrossel de bicicletas, puseram à roda a cabeça de um público entusiasmado. Mais tarde, no grande auditório do Centro Cultural de Belém, com Giroflé libertaram toda a sua poesia e delicada melodia e transportaram o público para um espaço entre a terra e o céu.

Chamem-Ihe o que quiserem, já o disse. Continuarei a acreditar que a arte se partilha e, como tal, se sente. Pela via da razão ou pela via da emoção, o que verdadeiramente mais desejo é continuar a fotografar, comunicando que há ainda muitas e boas razões para, intensamente, abraçar esta vida.

Em La Ferme d'en Haut, Villeneuve d' Ascq, Lille, Abril de 2005 


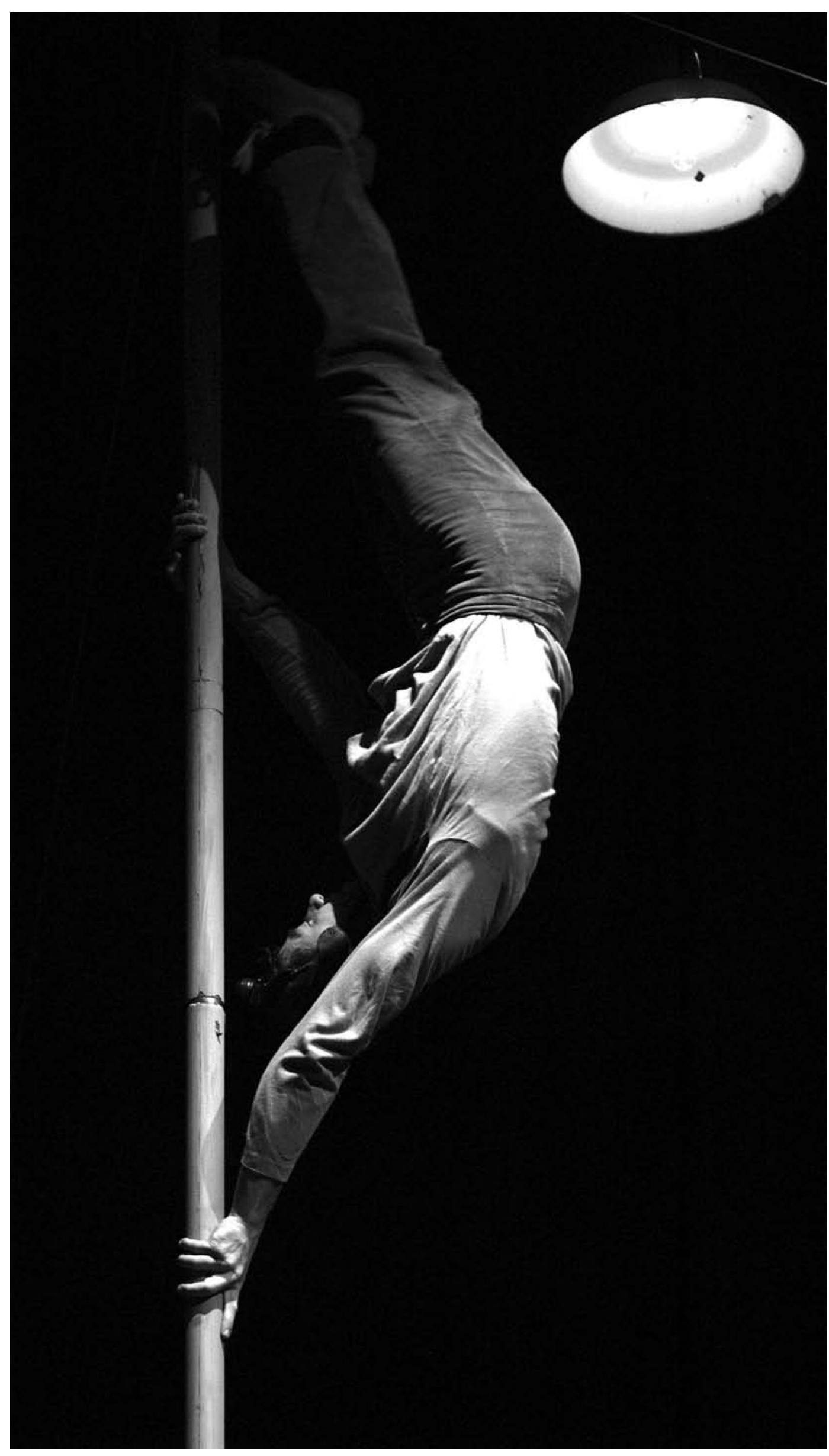


vinte e seis

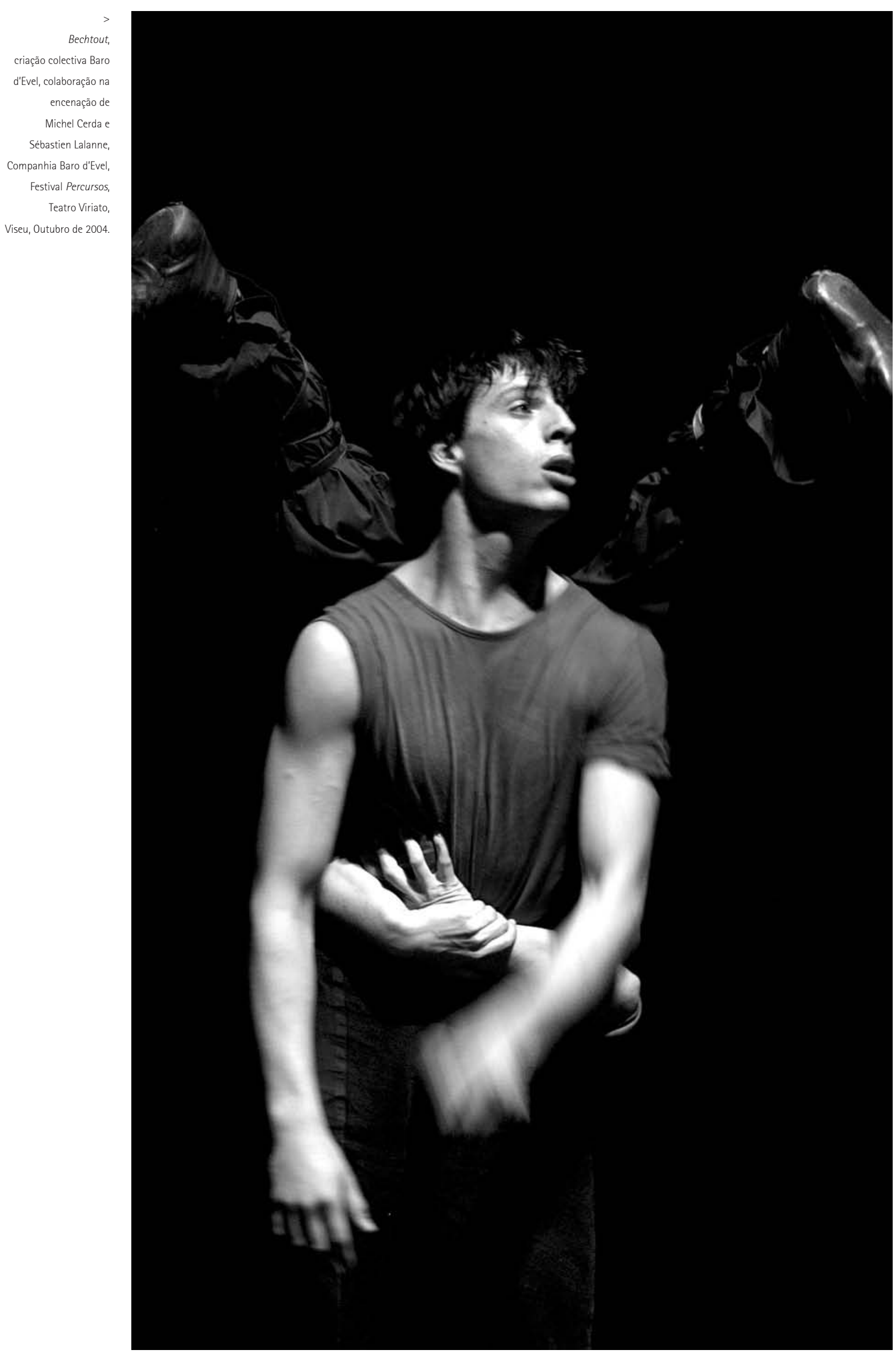




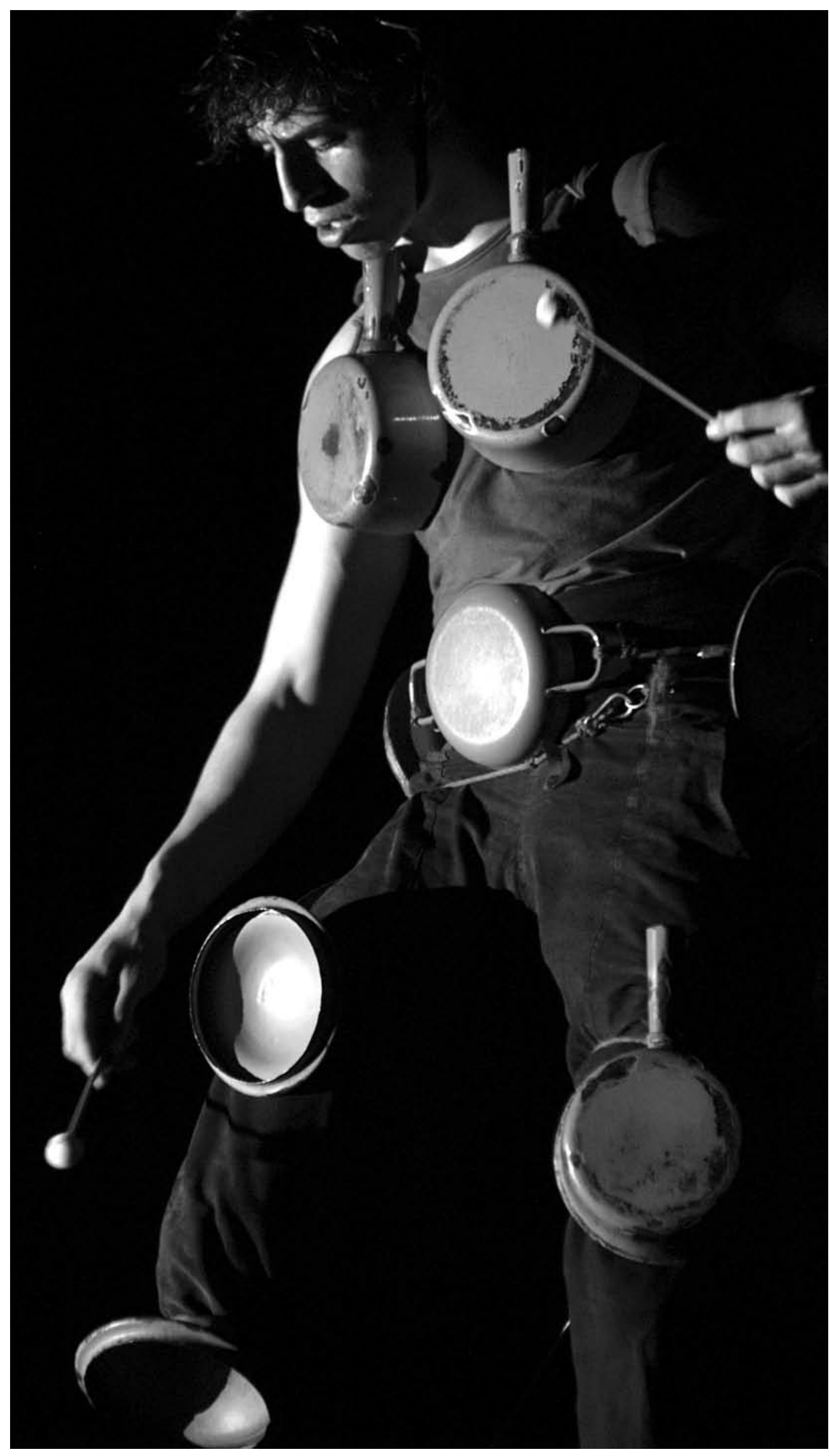



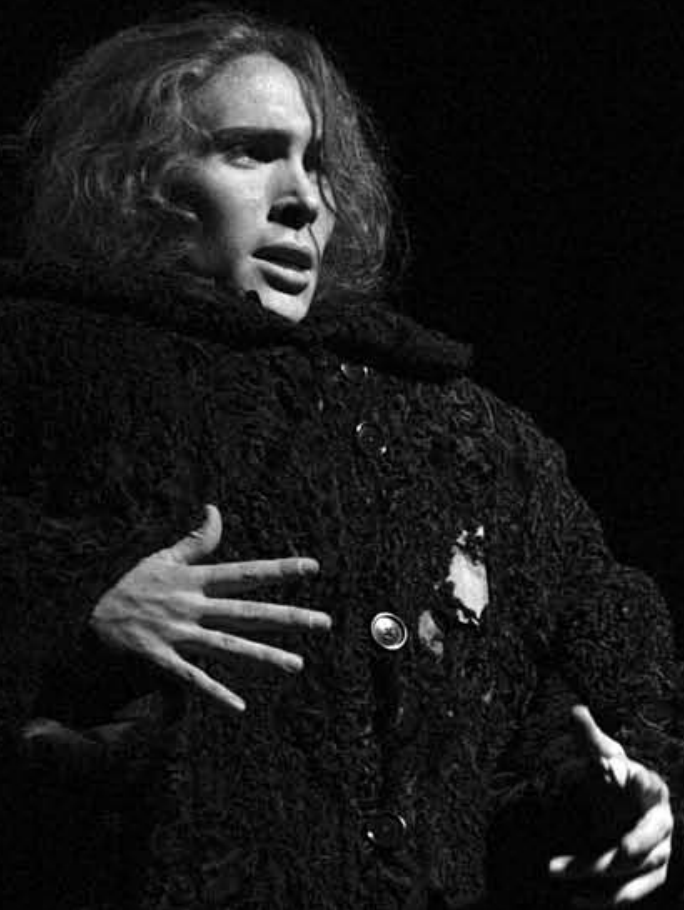

$+\pi$

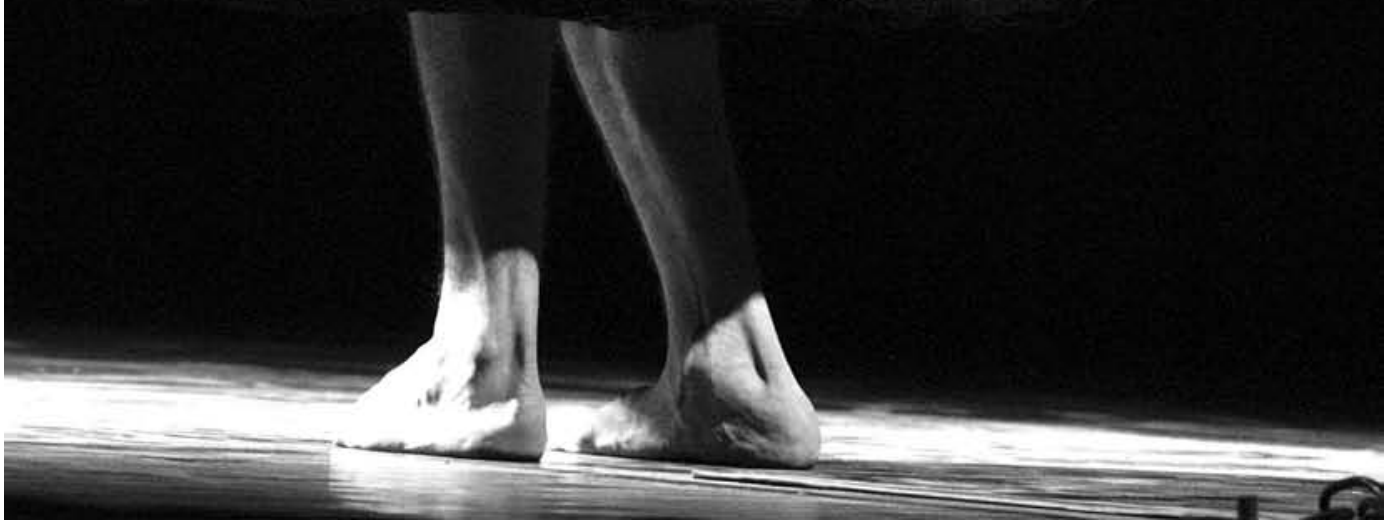



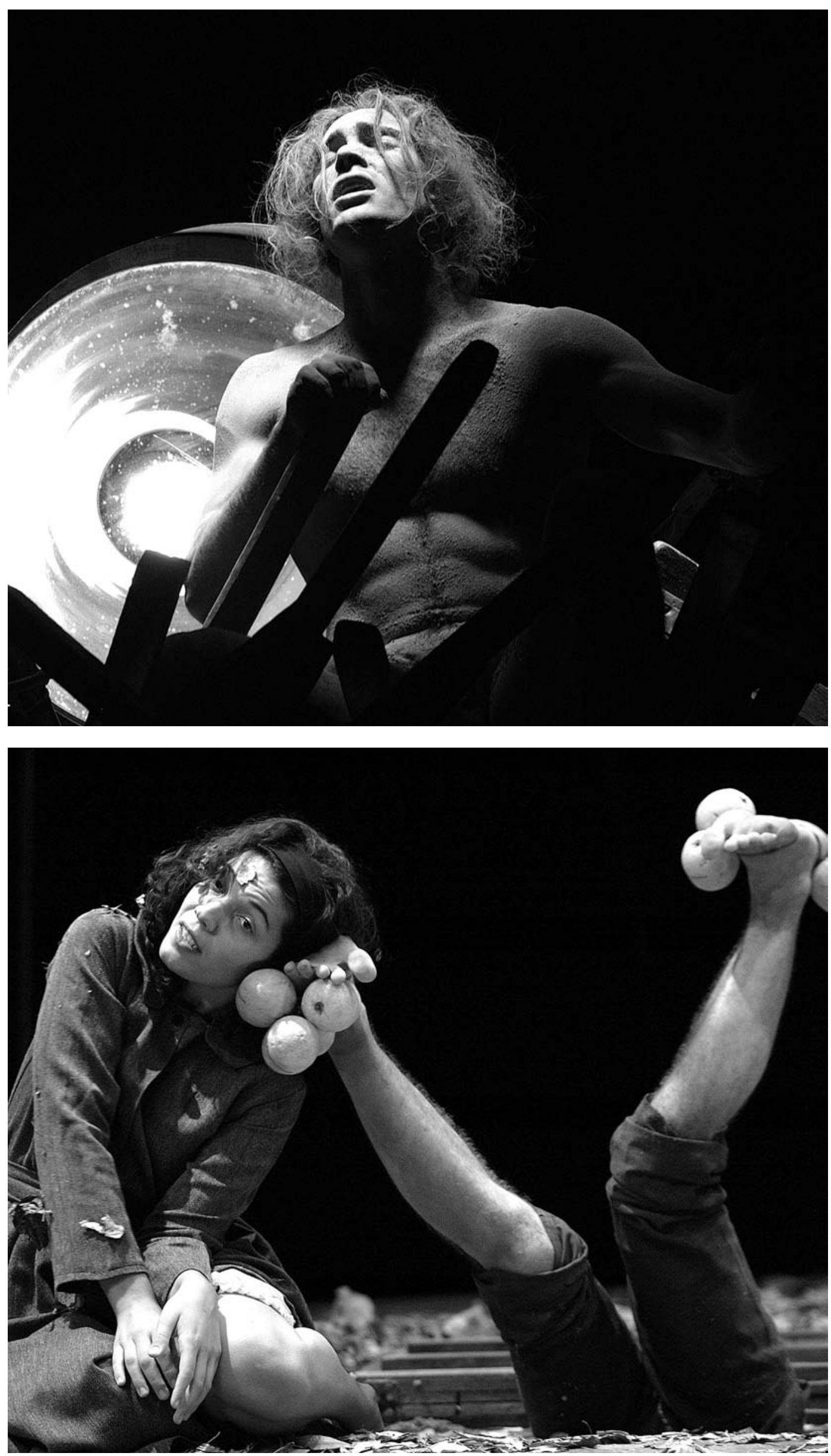


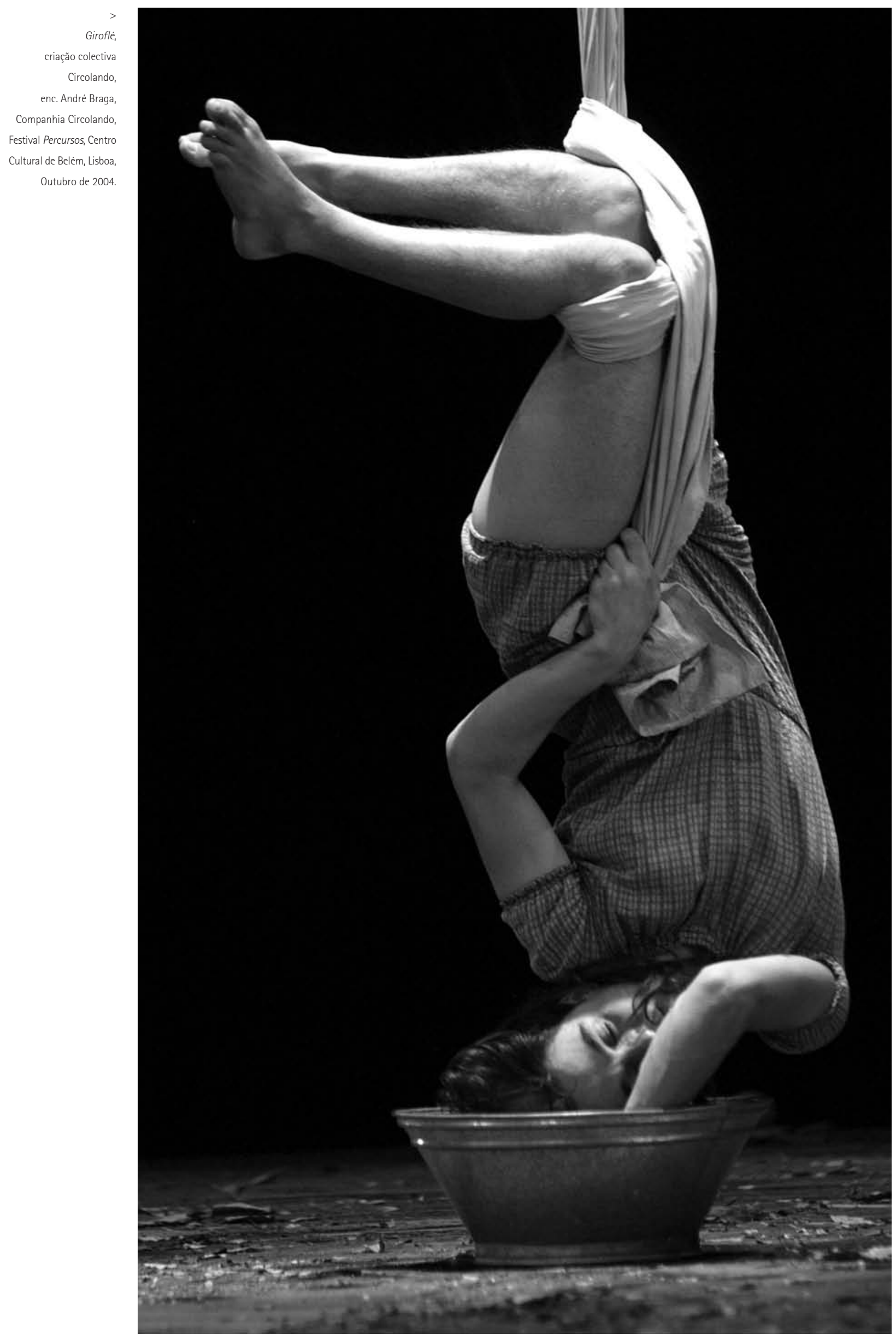




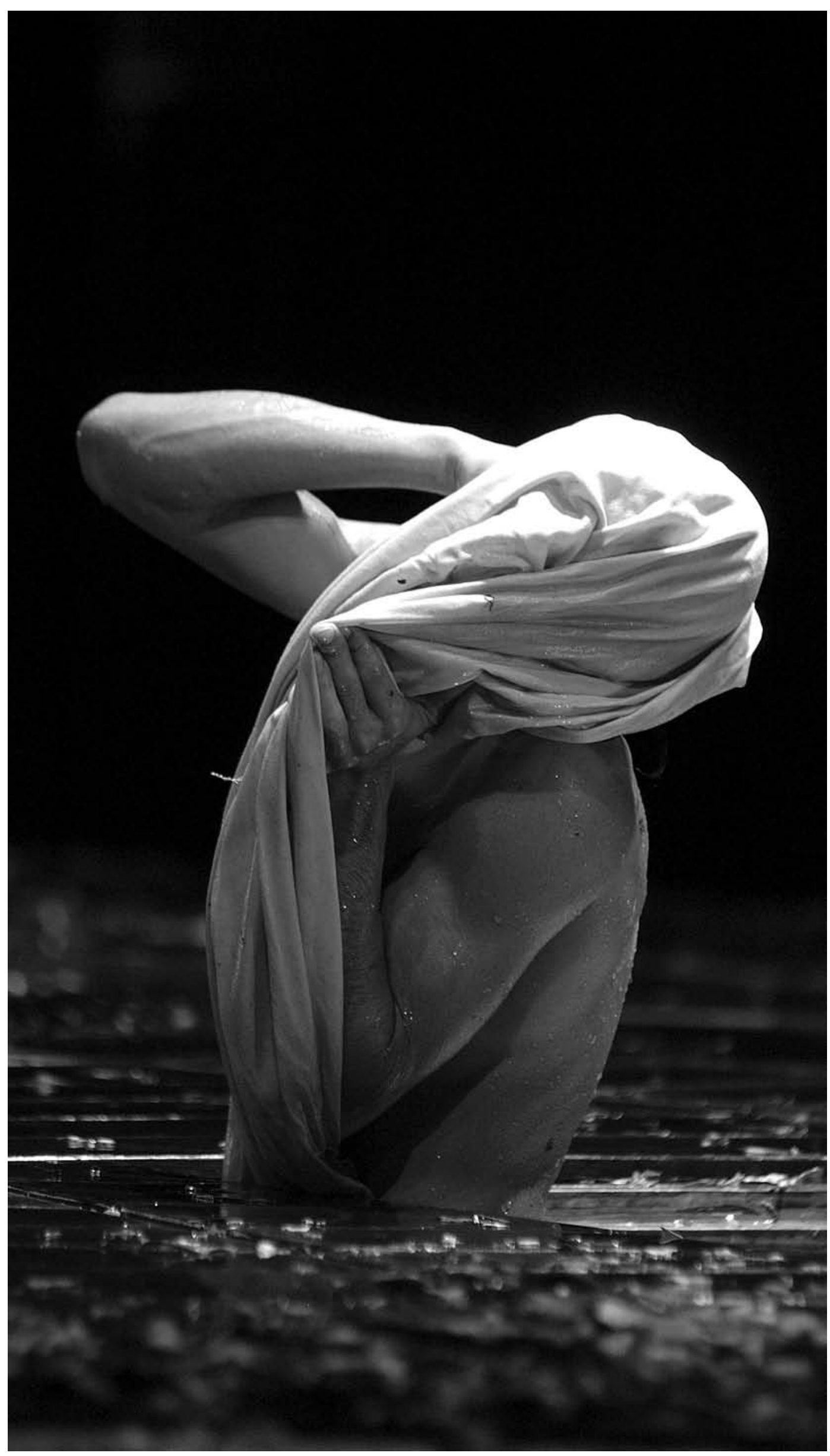




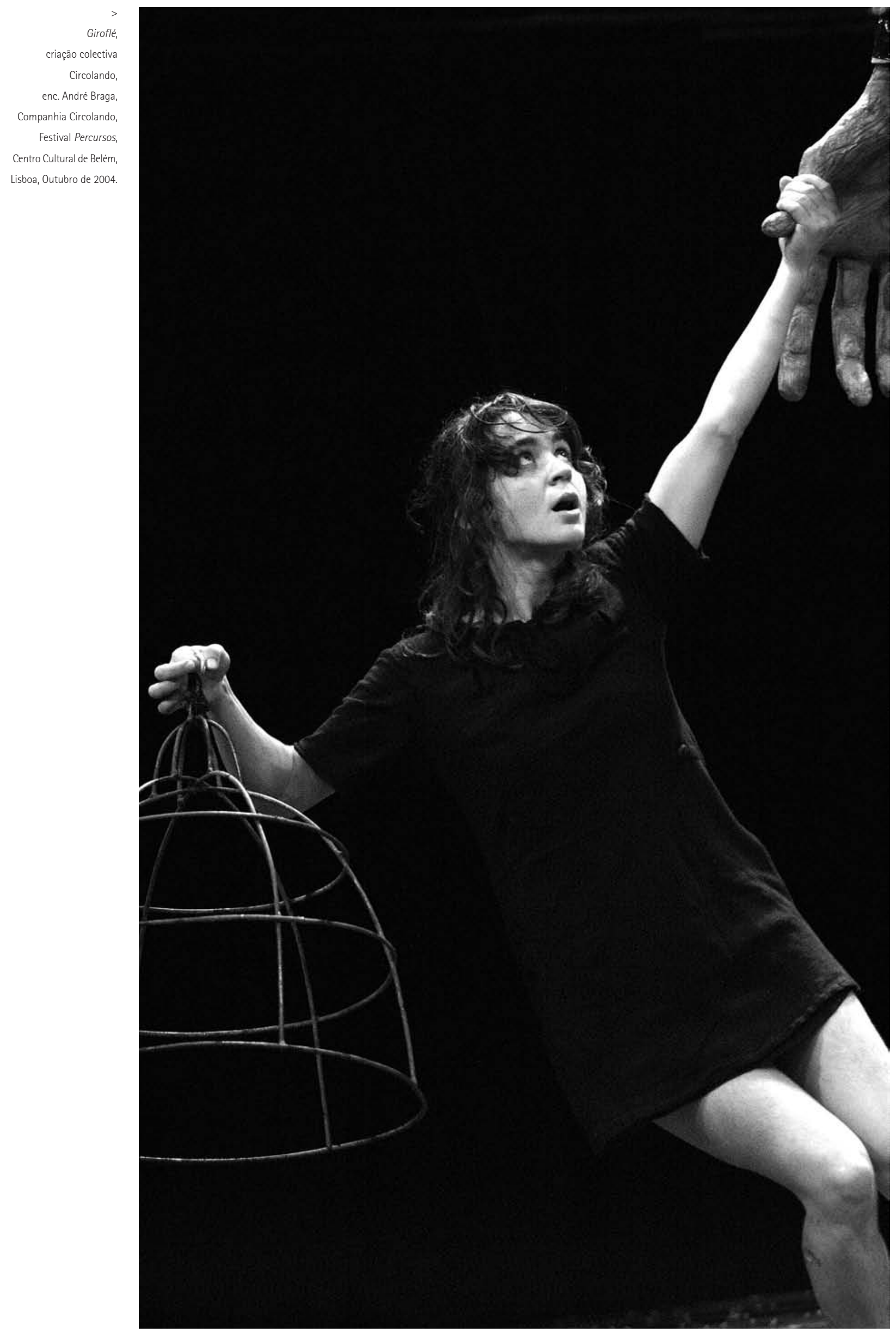




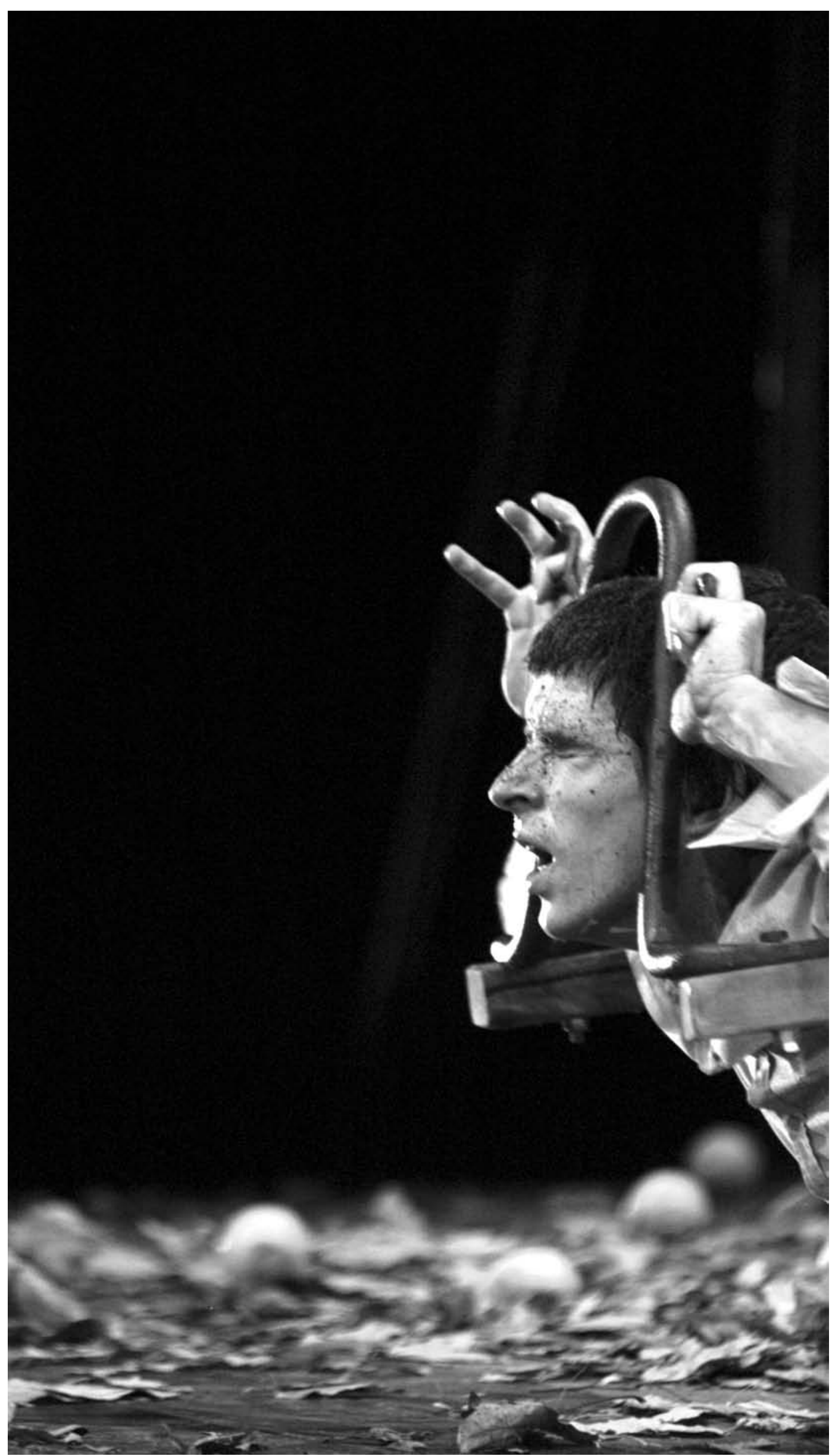


\begin{tabular}{l|l|l|l|l} 
trinta e quatro & Sinais de cena 3.2005 & Portefólio & Susana Paiva / Percursos CCB
\end{tabular}
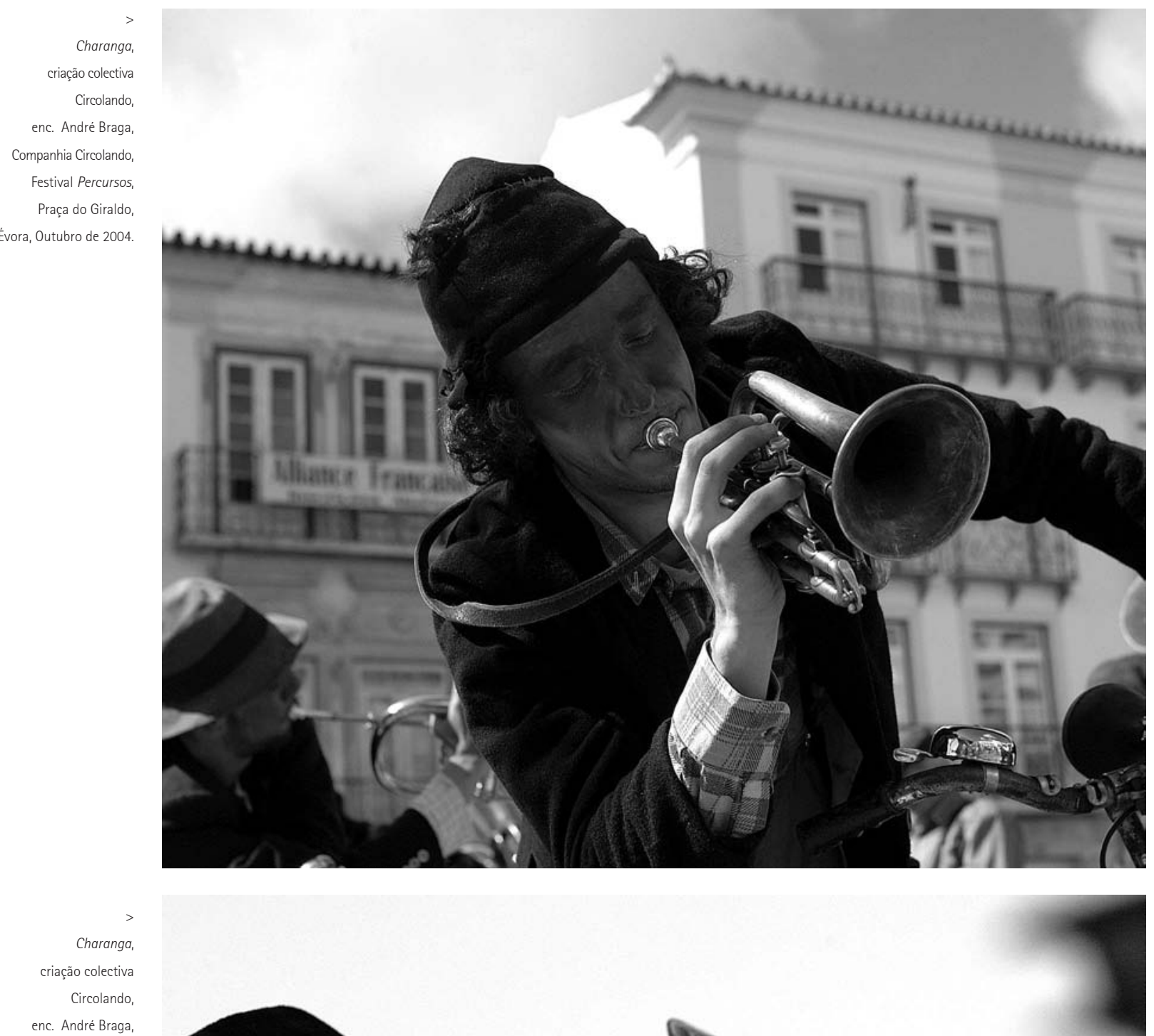

Companhia Circolando,

Festival Percursos,

Praça do Giraldo, Évora, Outubro de 2004.

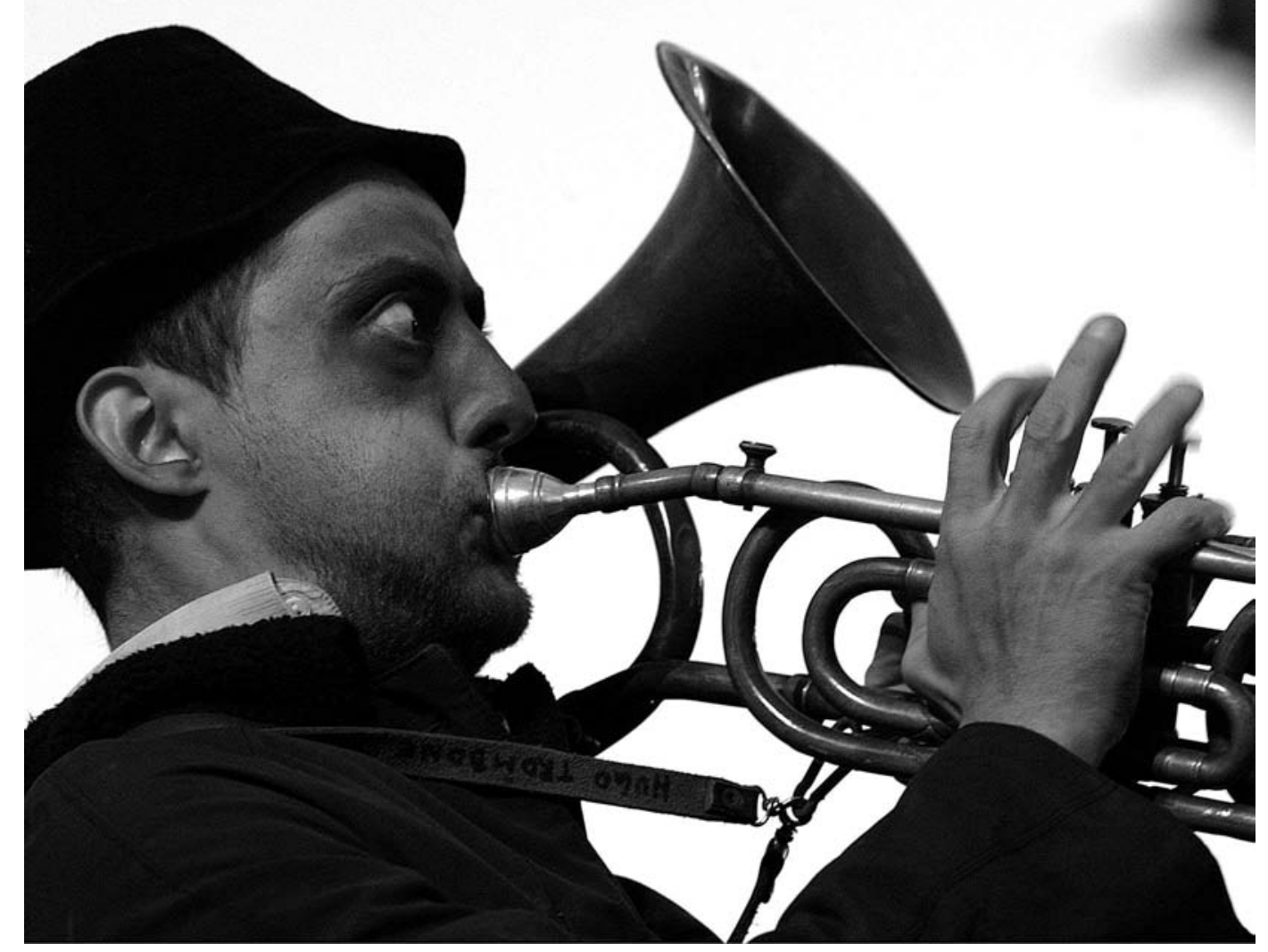

